\title{
Synthesis of Anion Starch Polymer Microsphere and its Adsorption Properties for Metal lons
}

\author{
Yang Zhao ${ }^{\mathrm{a}}{ }^{*}$, Yongming Zhang ${ }^{\mathrm{b}}$ and Xiaoping Huo ${ }^{\mathrm{c}}$ \\ Xijing University, Xi'an, Shanxi Province, 710123, PR China \\ azhaoyang@xijing.edu.cn, bzhangyongming@xijing.edu.cn, chuoxiaoping@xijing.edu.cn
}

Keywords: Polymer microsphere; Synthesis; Adsorption; Metal ions

\begin{abstract}
The anion starch polymer microspheres were made of neutral starch microsphere by the secondary polymerization and an ionization using $\mathrm{Na}_{3} \mathrm{P}_{3} \mathrm{O}_{9}$ as the anion reagent. The anion starch polymer microsphere was characterized by Laser Particle Analyzer and FT-IR spectroscopy. Adsorption behavior of anion starch polymer microsphere for metal ions was investigated by atomic absorption spectrophotometry. The results showed that two kinds of crosslinking agent $\mathrm{N}$, $\mathrm{N}$-methylenebisacrylamide and $\mathrm{Na}_{3} \mathrm{P}_{3} \mathrm{O}_{9}$ were definitely cross-linked with glucose group, and the average particle diameter of anion starch polymer microsphere was about $47.8 \mu \mathrm{m}$, which had a small average particle size. And the starch based polymer microsphere exhibited better adsorption property for copper ions.
\end{abstract}

\section{Introduction}

Anion starch polymer microsphere was a kind of artificial natural starch derivatives, which was synthesized by anion modification [1-4]. The adsorption ability of this polymer microsphere may enhance by grafted the anionic group, especially could absorbed the some substance with cationic group [5, 6]. Meanwhile, this polymer microsphere with nontoxic and environmentally friendly could be used as metal ion adsorbent, which would not result in secondary pollution. Therefore, anion starch polymer microsphere, a type of adsorption material, could be used for some huge development potential fields, such as metal ions adsorption separation and waste water treatment. However, the adsorption property of anion starch polymer microsphere for metal ions had not been yet studied [7-10].

In this paper, the anion starch polymer microsphere was synthesized by reversed phrase emulsion system, used $\mathrm{N}, \mathrm{N}^{\prime}-$-methylenebisacrylamide and $\mathrm{Na}_{3} \mathrm{P}_{3} \mathrm{O}_{9}$ as the cross linking agent, initiated by potassium persulphate-sodium bisulfite, span-60 and tween-60 served as emulsifier, approached to the preparation and formation mechanisms of microsphere. The anion starch polymer microsphere was characterized by laser particle size analyzer and FT-IR spectroscopy. Also, the adsorption property of this polymer microsphere for $\mathrm{Cu}^{2+}, \mathrm{Cr}^{3+}$ and $\mathrm{Cd}^{2+}$ were studied.

\section{Experiment}

Preparation of Anion Starch Polymer Microsphere. Soluble starch (Jungle Chemical Works, SiChuan, China), Cyclohexane, chloroform, sodium hydroxide, ethyl acetate, acetone, alcohol, Span-60, Tween-60, $\mathrm{K}_{2} \mathrm{~S}_{2} \mathrm{O}_{8}, \mathrm{NaHSO}_{3}, \mathrm{~N}, \mathrm{~N}$--methylenebisacrylamide, were used to prepare the anion starch polymer microspheres and all reaction reagents were analytical. Firstly, $2 \mathrm{~g}$ Span-60 and Tween-60 dispersed in $120 \mathrm{~mL}$ hex methylene with mechanical stirring. This solution was added to three-necked flask, and was heated to $80{ }^{\circ} \mathrm{C}$ with continuously stirred. $2 \mathrm{~g}$ soluble starch was dissolved in $20 \mathrm{~mL}$ distilled water in $80{ }^{\circ} \mathrm{C}$ and remained for 30 minutes to completely dissolve starch. Secondly, this dissolve starch was added to the three-necked flask with continuously stirred and at $80^{\circ} \mathrm{C}$ to obtained reversed emulsion. $0.2 \mathrm{~g}$ of $\mathrm{N}, \mathrm{N}$ '-methylenebisacrylamide was dissolved in $30 \mathrm{~mL}$ chloroform in a three-necked flask which was deoxygenated using nitrogen prior to be used. 
$0.04 \mathrm{~g} \quad \mathrm{~K}_{2} \mathrm{~S}_{2} \mathrm{O}_{8}$ and $0.03 \mathrm{~g} \quad \mathrm{NaHSO}_{3}$ were then added into the $\mathrm{N}$, $\mathrm{N}$-methylenebisacrylamide/chloroform solution. The resultant solution was mixed at $50{ }^{\circ} \mathrm{C}$ for 2 hours. The product was obtained after centrifugal separation and dry $5 \mathrm{~h}$ by vacuum drying oven. Finally, this product which was neutral starch based polymer microsphere added to $\mathrm{Na}_{3} \mathrm{P}_{3} \mathrm{O}_{9}$ solution containing $\mathrm{NaOH}$ for $12 \mathrm{~h}$, and washed by ethanol several times. And then, anion starch polymer microsphere was obtained by drying $5 \mathrm{~h}$ with $120^{\circ} \mathrm{C}$.

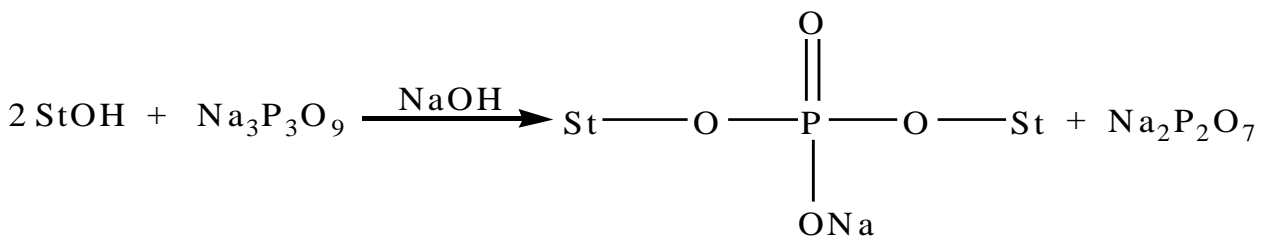

Scheme 1. Anion - modified of starch polymer microsphere

Characterization Techniques. Particle size distribution of anion starch polymer microsphere was measured by Laser Particle Analyzer. The chemical structure of anion starch polymer microsphere was characterized by FT-IR spectroscopy.

Adsorption Experiment. A large number of $25 \mathrm{~mL}$ of $\mathrm{Cu}\left(\mathrm{NO}_{3}\right)_{2}, \mathrm{Cr}\left(\mathrm{NO}_{3}\right)_{3}$ and $\mathrm{Cd}\left(\mathrm{NO}_{3}\right)_{2}$ solutions were placed into conical flasks with plug, and $0.1 \mathrm{~g}$ of anion starch polymer microsphere was added into these solutions, respectively. These conical flasks were placed in a constant temperature oscillator and were shaken. At different time intervals, the mixtures were taken out, respectively, and after centrifugal separation, the $\mathrm{Cu}^{2+}, \mathrm{Cr}^{3+}$ and $\mathrm{Cd}^{2+}$ concentrations in the supernatants were determined by atomic absorption spectrophotometer. And then the corresponding adsorption amounts were calculated. The equilibrium adsorption capacity was calculated according to the following Eq. 1.

$$
Q_{e}=\frac{\left(c_{0}-c_{e}\right) V}{m}
$$

Where $\mathrm{Q}_{\mathrm{e}}, \mathrm{c}_{0}, \mathrm{c}_{\mathrm{e}}, \mathrm{V}$, and $\mathrm{m}$ were the equilibrium adsorption capacity (mmol/g), the initial concentration of $\mathrm{Cu}^{2+}, \mathrm{Cr}^{3+}$ and $\mathrm{Cd}^{2+}(\mathrm{mmol} / \mathrm{L})$, the equilibrium concentration of $\mathrm{Cu}^{2+}, \mathrm{Cr}^{3+}$ and $\mathrm{Cd}^{2+}$ $(\mathrm{mmol} / \mathrm{L})$, the solution volume $(\mathrm{L})$, and the mass of anion starch polymer microsphere $(\mathrm{g})$, respectively.

\section{Results and Discussion}

Particle size distribution of anion starch polymer microsphere was shown in Fig. 1. It could be seen that average grain diameter of this polymer microsphere was $47.8 \mu \mathrm{m}$, which had a small average particle size and a narrow distribution.

The FT-IR spectrum of anion starch polymer microsphere was shown in Fig. 2. It showed clearly that the characteristic peaks at $1647 \mathrm{~cm}^{-1}$ were attributed to overlap the stretching vibration of $\mathrm{C}=\mathrm{O}$ and stretching vibration of acyl amide, which could be deduced logically that the starch had definitely cross-linked with N, N'-methylenebisacrylamide. 


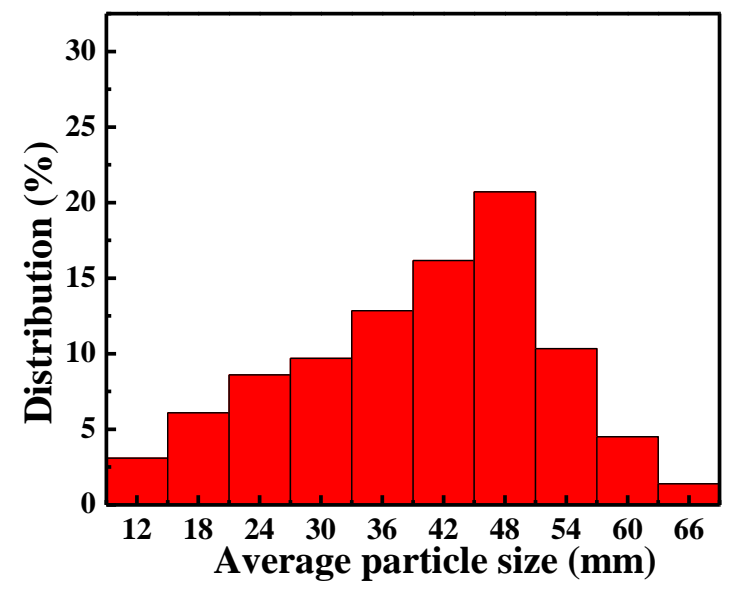

Figure 1. Particle size distribution of anion starch polymer microsphere

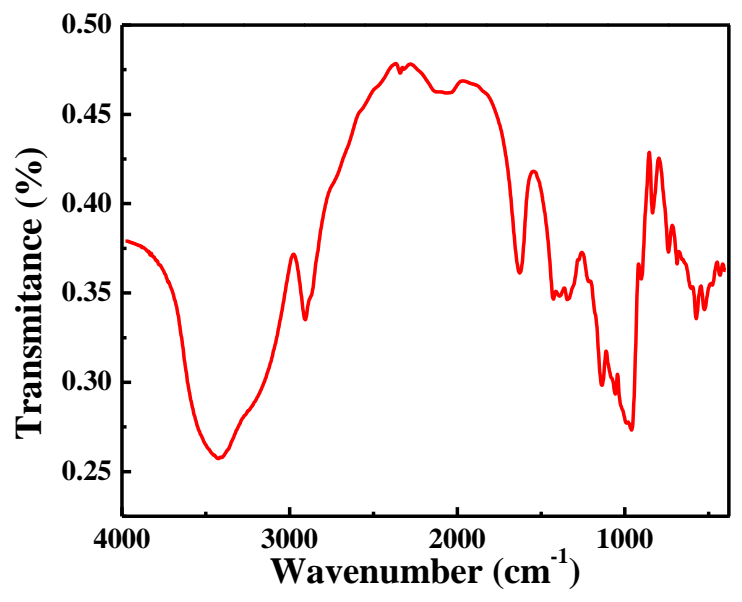

Figure 2. IR spectrogram of anion starch polymer microsphere

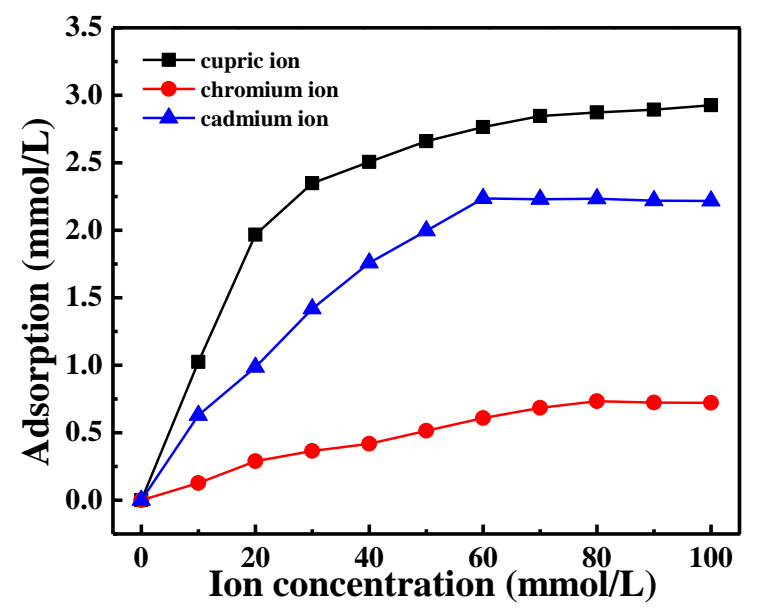

Figure 3. Adsorption isotherm of different ions on anion starch polymer microsphere

The isothermal adsorption curves of $\mathrm{Cu}\left(\mathrm{NO}_{3}\right)_{2}, \mathrm{Cr}\left(\mathrm{NO}_{3}\right)_{3}$ and $\mathrm{Cd}\left(\mathrm{NO}_{3}\right)_{2}$ on anion starch polymer microsphere at $298 \mathrm{~K}$ were shown in Fig. 3. With the increase of the initial concentration of the metal ions, adsorption capacity of anion starch polymer microsphere for lead ions, chromium ions and cadmium ions became increased rapidly. When the initial concentration increased to $60 \mathrm{mmol} / \mathrm{L}$, 
the adsorption capacity of anion starch polymer microsphere increased slightly. It was shown that anion starch polymer microsphere exhibited good adsorption of copper ions.

\section{Summary}

The anion starch polymer microsphere was successfully prepared by inverse suspension system. The FT-IR spectroscopy results showed that two kinds of crosslinking agent N, $\mathrm{N}$ '-methylenebisacrylamide and $\mathrm{Na}_{3} \mathrm{P}_{3} \mathrm{O}_{9}$ were definitely cross-linked with glcosyl group. The average particle size of starch based polymer microsphere was about $47.8 \mu \mathrm{m}$, which had a narrow distribution size. Meanwhile, the adsorption capacity of anion starch polymer microsphere for copper ions, chromium ions and cadmium ions had been studied. This polymer microsphere exhibited good adsorption capacity for metal ions, especially copper ions, which could be applied in the field of water treatment.

\section{Acknowledgements}

This work was supported by Scholastic Science Research Foundation of Xijing University (Grant No. XJ140222).

\section{References}

[1] X.Q. Chen, J.L. Cao and X.J. Du: Journal of Functional Materials, Vol. 44 (2013) No.9, p.1309. (In Chinese)

[2] Y. Watcharatewinkul, C. Puttanlek and V. Rungsardthong: Carbohydrate Polymers, Vol. 75 (2009) No.3, p. 505.

[3] S. Song, C. Vieille: Applied Microbiology and Biotechnology. Vol. 84 (2009) No.1, p. 55.

[4] L. Zhang, J. Bai and H. Lian: Journal of Macromolecular Science, Part B, Vol. 53 (2014) No.1, p.142.

[5] C. Zhou, W. Zhang and M. Xia: Journal of Nano science and Nanotechnology, Vole, 13 (2014) No.7, p.4627.

[6] Q.Y. Shi, Z.J. Li and W. Yang: Technology of Water Treatment, Vole, 37 (2011) No.2, p.14. (In Chinese)

[7] K.B. Li, Y.D. Shen and G.Q. Fei: Journal of Functional Materials, Vol. 45 (2014) No.10, p.10113. (In Chinese)

[8] Z.R. Xin: Introduction of Functional Polymer (China Petrochemical Press, China 2009), p.106. (In Chinese)

[9] Q.Y. Shi, W. Yang and Z.J. Li: New Chemical Materials, Vol, 39 (2011) No.2, p.50. (In Chinese)

[10] G.H. Ma: Polymer Microsphere (Chemical Industry Press, China 2005), p.4. (In Chinese) 